\title{
Considerable cracking in the foundation slab in a multi-storey underground garage
}

\author{
Marek Maj ${ }^{*}$, Tomasz Kowalik and Andrzej Ubysz \\ Wroclaw University of Science and Technology, Wybrzeże Wyspiańskiego 27, 50370 \\ Wrocław
}

\begin{abstract}
Multilevel underground garages are often an ambitious geotechnical task in urban agglomeration. Lower levels of foundation slabs are often located below the groundwater level, which requires effective protection of the structure against groundwater invasion. The constructor's task is to design slabs and walls so that no cracks will form to allow groundwater infiltration. In practice, this requires the development of a correct recipe for concrete; moreover, all factors affecting the total state of normal and tangential stresses as well as technologies allowing for correct execution of the facility must be considered. Additionally, long-term destructive factors ought to be taken into account. The article presents problems that arose during the use of an underground garage, which occurred as a result of failure to take into account at the design stage some rheological processes, as well as the assessment of the possibility of using the facility despite the damage.
\end{abstract}

\section{Introduction - general description of the facility}

Multilevel underground garages are an important element of urban agglomerations. Their construction, however, requires a strict technological process to protect the surroundings [1] as well as walls securing the excavation during its use [2]. Protecting the facility against infiltration of groundwater is a particularly difficult task; both against groundwater shown in the geotechnical documentation [3, 4] and, more importantly, against water accumulating in the vicinity of the facility after its construction $[5,6]$. The paper presents problems with the use of the facility that occurred in one of the municipal underground car parks. After a few years of use, in some of the lowest spots, groundwater infiltration occurred. The phenomenon was slow; however, the observations on a monthly basis showed the necessity to determine the reasons for this pre-emergency condition and the performance of protective work [7]. The paper describes the construction of the bottom slab and the floor, as well as possible causes of cracks and dampness [8]. The analysis was made on the basis of research on the facility and scientific studies presenting the actual state of stresses in the structure as well as rheological processes.

The building, whose floor and foundation slab is subject to technical evaluation, has several above-ground storeys, designed mainly for architectural offices and two underground

\footnotetext{
* Corresponding author: marek.maj@pwr.edu.pl
} 
storeys for garages. The building has a slab-and-column construction, with spacing of columns in axes of $8.1 \mathrm{~m}$ and dimensions $0.8 \times 0.8 \mathrm{~m} \mathrm{x} \mathrm{m}$. The ceilings are monolithic with a thickness of $0.4 \mathrm{~m}$ and $0.5 \mathrm{~m}$. The building area of the underground part is approximately $4500 \mathrm{~m}^{2}$. The facility is located over 8 meters below ground level. The investment was designed on the plan of the letter $L$ with a characteristic arched bend, which emphasizes the main entrance to the office building and the intersection of the main communication routes. It is a building with modern as well as timeless architecture, in which the investor planned 300 parking spaces. Failure occurred in the concrete floor with a thickness of $0.15 \mathrm{~m}$ at the lowest level of the underground garage, laid on a reinforced concrete slab with variable thickness from $0.80 \mathrm{~m}$ to $1.30 \mathrm{~m}$ (Fig.1). According to the Construction Log, acceptance of the foundation slab reinforcement and permission for concreting was given in 2013 and since then the foundation slab is regarded to have been formed.

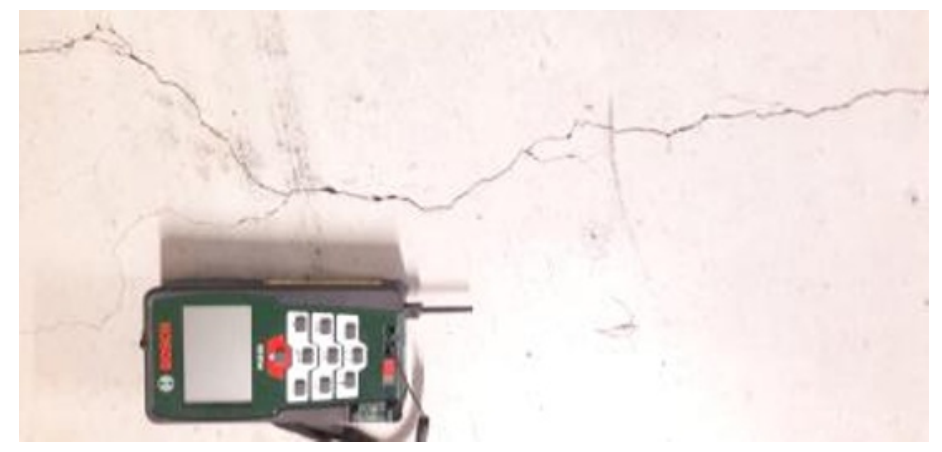

Fig. 1. Cracks in the parking slab with a width of over $0.6 \mathrm{~mm}$

\section{Geotechnical conditions}

The soil of the research area is made up of quaternary non-cohesive soils represented by fine sands lined with clay, sandy clay, loamy sand and dust, medium sands, medium sands with gravel, medium sands with clay, medium sand lined with clay sand gravel as well as loamy gravel sands, poorly compacted soils with sandy dust, cohesive soils represented by silty clays, compacted clays, clays, sandy clays, silty clays and organic cohesive soils in the form of clayey silts. They are covered from the top with a layer of uncontrolled embankments and spots of soil. The site has been determined to have the first quaternary aquifer. There's groundwater table at a depth of $-4.7 \div-6.8 \mathrm{~m}$ (below ground level). The groundwater table is tight and stabilizes at a depth of $-3.9 \div-4.5 \mathrm{~m}$. The tightening layer is made up of fine sands lined with clay, sandy clay and dust (silts), which are marked by varied permeability. Due to the lack of a poorly permeable layer insulating the aquifer from the surface, fluctuations in the groundwater table within $\pm 0.5 \mathrm{~m}$ can be expected. In addition, groundwater filtration was found in all openings in the area of fine sands lined with clay, sandy clay and dust (silt). The filtration occurs at a depth of $-5.2 \div-4.9 \mathrm{~m}$.

\section{Foundation slab and concrete floor}

The foundation slab was built in the so-called 'white bathtub technology' (uncoated waterproofing of the underground storeys of the facility). The slab has the shape of a trapezoid with the dimensions of two parallel sides $65 \mathrm{~m}$ and $24 \mathrm{~m}$ and a long perpendicular one $116 \mathrm{~m}$ long. Concrete class $\mathrm{C} 30 / 37$, water resistance $\mathrm{W} 8, \mathrm{~W} / \mathrm{C}$ ratio $<0.45$. 
The thickness of the slab is variable, usually outside the areas of structural columns of the building's frame, it is $0.80 \mathrm{~m}$, and under the columns, it is normally $1.20 \mathrm{~m}$, and in some cases $1.35 \mathrm{~m}$. The concrete cover of the foundation slab is $40 \div 50 \mathrm{~mm}$. The concrete cover of the foundation wall is $3.5 \mathrm{~cm}$. The slab is circumferentially fixed in the diaphragm wall by means of dowel joints, the diaphragm wall thickness being $0.80 \mathrm{~m}$. The connection with the diaphragm wall is sealed by a system of injection tubes. The injection process was multi-stage in its character, depending on the construction stage. The diaphragm wall is in its bottom part fixed in an impermeable layer of soil. The foundation slab is loaded with reinforced concrete pillars and shields of lift shafts, utility rooms, etc.

The building has a structural dilatation at a distance of $50 \mathrm{~m}$ from the western edge of the slab. A lot of dilatation and work breaks were designed. The average distance between dilatation is $8 \mathrm{~m}$. The sealing of expansion joints in the panels and walls was made with the use of strips, sheet metal and sealing pipes. PVC sealing profiles were used to facilitate the creation and insulation of shrinkage and working dilatations. Trapezoidal sheets were installed along the axes of the planned working dilatations.

Reinforcement of the foundation slab is compatible in terms of elasticity and resilience with a large amount of reinforcement in thickened parts of the slab and at the location of reinforced concrete pillars. In the middle of the span between pillars, the static and anti-shrink reinforcement combined in both directions, at the bottom and at the top (double symmetrical and orthogonal reinforcement) is $\phi 20$ every $22 \mathrm{~cm}$, which gives $\rho 1=\rho 2=\mathrm{A}_{\mathrm{s}} / \mathrm{A}_{\mathrm{c}}=0.2 \%$.

The minimum required reinforcement for reinforced concrete slabs is $0.2 \%$ and anti-shrink according to old standards is also $0.2 \%$. The minimum surface anti-shrink reinforcement that inhibits the cracking process is calculated in accordance with [9] $\rho^{\mathrm{s}} \min =0.48 \div 0.76 \%$.

From the description [3], it can be concluded that the calculated minimum anti-shrink reinforcement for all elements is $3.35 \mathrm{~cm}^{2} / \mathrm{m}$, and it was included within the main reinforcement, i.e. the anti-shrink reinforcement was not used. The allowable width of construction cracks was $0.3 \mathrm{~mm}$. It should be noted that only cracks up to $0.1 \mathrm{~mm}$ wide can be considered as self-sealing.

According to the description in the documentation [3] in the concreting works, no breaks during the concreting were prolonged above $20 \mathrm{~min}$; the concreting temperature was in the range of $-8{ }^{\circ} \mathrm{C}$ to $30{ }^{\circ} \mathrm{C}$.

Protection of the foundation slab consisted in covering the surface of the slab with maintenance foil and then flooding it with water. Efforts were made in order to keep the water table on the surface of the slab not less than $2 \mathrm{~cm}$.

The sealing of the diaphragm wall through the contact inserts in the wall and between the foundation slab and the wall was carried out in 2014. After each major downpour, cracks in the wall were injected. The number of cracks was getting smaller and smaller.

After about one year from the time of laying the foundation slab (according to the Construction Log), the concrete floor was made with the following layers:

- the first surface layer with a thickness of $0.3 \mathrm{~cm}$ from polyurethane;

- the second layer of $0.14 \div 0.16 \mathrm{~m}$ is a C20/25 concrete topping reinforced with co-polymer fibre in an amount of $1.5 \mathrm{~kg} / \mathrm{m}^{3}$, reinforced with a steel mesh $\phi 6$ every $0.15 \mathrm{~m}$;

- bonding layer was put on the foundation slab.

\section{Operating conditions}

After every major rainfall, leakage of groundwater through the diaphragm wall is observed. This indicates damming up of groundwater and the difficulties it has flowing around the building during atmospheric precipitation as well as leaks in the connections of individual 
segments of the diaphragm wall. Local dampness is also observed at the connection points of the diaphragm wall with the foundation slab (Fig. 2). This means penetration of groundwater through some expander connections and through the walls. Leaks in the floor over the foundation slab are shown in Fig. 3. After every major atmospheric precipitation, it is necessary to perform injections in order to seal the walls in places of leaks.

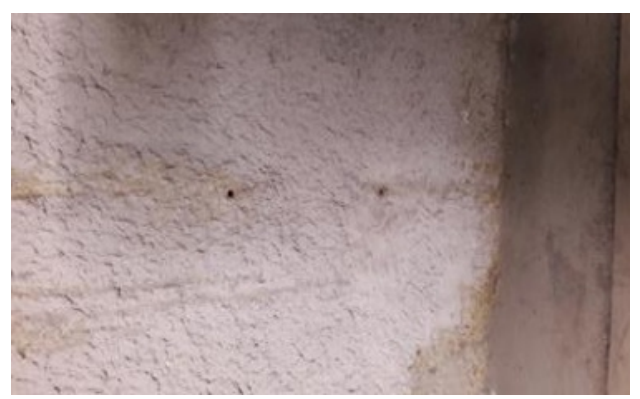

Fig. 2. Dampness in the connection between $\mathrm{t}$ he diaphragm wall to the foundation slab

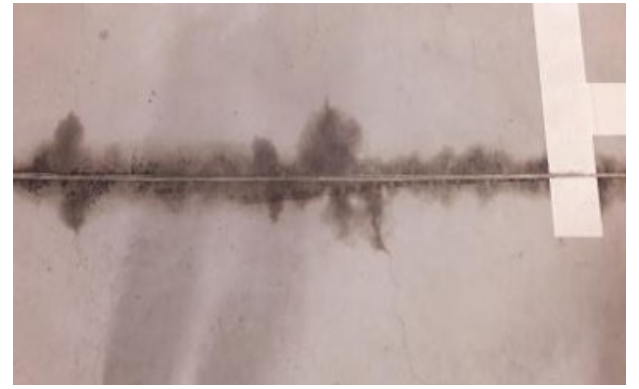

Fig. 3. Leaks in the floor over the foundation slab

The 'white bathtub technology' assumes tightness of diaphragm walls, foundation slab and connections between them. As can be seen from the documentation [3], the diaphragm wall basis was located in cohesive, tight soils, which, it was assumed, no groundwater would penetrate. Construction of underground garages, forming a bathtub with a height of over $8 \mathrm{~m}$ below ground level and approx. $4 \mathrm{~m}$ below groundwater level, poses the risk of groundwater accumulation. In addition, the diagonal position (in places) of successive permeable and impermeable layers may cause leakage of the cohesive soil layers and allow groundwater to come under the surface of the foundation slab. The curling effect deformations of the foundation slab connected to the diaphragm wall should be sealed with systemic injection pipes. Water leaks through diaphragm walls and cracks in the floor on the foundation slab indicate penetration of groundwater into the underground garage space in the area below groundwater level, in the places where the foundation meets the ground.

The static-and-strength calculations show that there is no danger of groundwater raising the foundation slab under the building and under the car park. The pressure of groundwater can cause pressure of about $40 \mathrm{kN} / \mathrm{m}^{2}$; the pressure upon the foundation slab under the building of is about $143 \mathrm{kN} / \mathrm{m}^{2}$ and under the part outside the building, it is about $55 \mathrm{kN} / \mathrm{m}^{2}$.

In addition, an ongoing process of crack propagation can be observed (according to the interview carried out with the user's representative); their number, width and aperture is gradually increasing. The distance between cracks, in places strongly outlined, the width of which is more than $0.1 \mathrm{~mm}$, is on average $0.40 \mathrm{~m}$.

\section{Analysis of the contraction phenomenon in the floor and the foundation slab}

The analysis was based on

- inspection on the site and interviews with the users of the facility;

- an inventory of damage to the floor;

- existing technical documentation (as-built);

- strength tests of concrete samples;

- static-and-strength calculations;

- photographic documentation. 


\subsection{Impact of shrinkage effect upon deformation and stress}

\section{Foundation plate}

From the information contained in the documentation [3], it can be concluded that the designer chose to neutralise the shrinkage effect, i.e. the tensile stress, by structural reinforcement, which entails ignoring any additional tensile stress in the concrete resulting from shrinkage. Additionally, the designer set the maximum permissible crack opening value equal to $\mathrm{W}_{\max }=0.3 \mathrm{~mm}$. In the case of 'cracking through,' it does not ensure tightness, which can be ensured up to a crack width of at most $\mathrm{wmax}=0.1 \mathrm{~mm}$. In the documentation received, the authors of this article did not find any records informing of stress calculations of contraction in the slab, which is why they carried out their own calculations. In general, contraction stresses in concrete have four components [9]:

(1) $\sigma_{\mathrm{cs}}{ }^{\mathrm{I}}$, derived from external bonds limiting free contraction;

(2) $\sigma_{\mathrm{cs}}{ }^{\text {IIa }}$ automatic (autogenous contraction), and $\sigma_{\mathrm{cs}}{ }^{\text {IIb }}$ from the drying stress;

(3) $\sigma_{\mathrm{cs}}$ III from self-strain;

(4) stresses due to carbonatation $\sigma_{\mathrm{cs}}{ }^{\mathrm{IV}}$.

If free deformation of the structure is somehow restricted (attachment of the elements at the ends), an additional tensile force may arise, associated with the shrinkage effects expressed in $\sigma_{\mathrm{cs}}{ }^{\mathrm{I}}$ stresses. In the $\sigma_{\mathrm{cs}}{ }^{\mathrm{I}}$ part of the contraction, we distinguish the contraction from blocked internal ties as well as external ties. If we assume that between particular parts of the foundation slab separated by technological gaps, there is a mutual limit of displacements resulting from cooperation with reinforcing bars, we can estimate additional stresses $\sigma_{\mathrm{cs}}{ }^{\mathrm{I}}$ with a value from $2.64 \mathrm{MPa}$ to $5.31 \mathrm{MPa}$. Then the expected total tensions from contraction are in the range between $2.94 \mathrm{MPa}$ and $6.39 \mathrm{MPa}$. It should be noted that the characteristic tensile strength of concrete is $\mathrm{f}_{\text {ctk }}=2.0 \mathrm{MPa}$. This indicates the possibility of cracking, in particular in the initial phase of concrete maturation (the stress range is from $3.62 \mathrm{MPa}$ to $6.39 \mathrm{MPa}$ ).

In the case of the tested slab, contraction from drying $\sigma_{\mathrm{cs}}{ }^{\mathrm{II}}$ reaches, according to the authors' calculations, a value of about $0.24 \mathrm{MPa}$, which is about $12 \%$ of strength $\mathrm{f}_{\text {ctk. }}$. The influence of the element's massiveness expressed by the quotient of the element's double circumference to the surface area results in $\sigma_{\mathrm{c}}{ }^{\mathrm{III}}$ stresses. They appear at the beginning of concrete bonding and, according to our own calculations, they can be 0.74 $\mathrm{MPa}$ at the beginning of bonding and $0.35 \mathrm{MPa}$ at a later time of using the structure. The average sum of these stresses $\sigma_{\mathrm{cs}}{ }_{\mathrm{II}}+\sigma_{\mathrm{cs}} \mathrm{III}$ can range from 0.60 to $0.98 \mathrm{MPa}$. The autogenous and carbonatation contraction is ignored; to some extent, it can be added to contraction from drying out.

Based on the recommendations presented in [9], many authors suggest a computational section area of reinforcement preventing the appearance of cracking. The calculations carried out show that the reinforcement calculated according to these recommendations is greater than the reinforcement calculated in the design, hence the possibility of cracking.

To tensile stresses from contraction, stresses from permanent and variable loads affecting the structure of the building and transmitted to the slab are added. According to the designer, the floor made on the slab cooperates with it through the bonding layer.

In general, cracking causes relaxation of contraction stress, however, excessive cracking simultaneously reduces the stiffness of the structure and increases corrosion potential of the reinforcement. In his calculations, the designer allowed the creation of structural cracks in the slab with a width of up to $0.3 \mathrm{~mm}$. The majority of cracks observed in the surface of the concrete slab have a width greater than the assumed critical width. Moreover, attention needs to be paid to the fact that, as the base water dries up and periodically its pressure on the bottom of the slab increases, the process of crack widening does not stop. The cracking area will increase (mainly the width of the cracks), although smaller and smaller increments will be observed. 
Concrete floor on the foundation slab

The multi-layer concrete floor is strongly cracked. By using a bonding layer, it is structurally incorporated into the static-strength work of the foundation slab, being the upper part of the slab. Hence cracking of the floor initiated in the foundation slab is possible. The bonding layer was placed on the previously moistened substrate. One year after the slab is completed, it can be expected that its top layer has dried out to a depth of just over $0.15 \mathrm{~m}$. This means that the wetting of the slab has not moisturized the entire dried concrete layer, which can absorb a much larger volume of water, and during the maturing of concrete in the floor, draw water from the floor. Water permeability properties for the bonding layer according to Technical Specification are not determined.

On the basis of three boreholes, homogeneous concrete was found without signs of aggregate fraction settling and evenly distributed co-polymer fibres. The floor has been carefully laid, the upper layer being properly covered with resin firmly adhering to the concrete, without significant signs of protective coating wear.

The floor, laid on a foundation slab made much earlier, is itself subject to contraction due to drying out. It has the same components of contraction that previously occurred in the slab. In the foundation slab, free contraction is restrained by the structural reinforcement, while in the floor, the contraction is blocked by its cooperation with the slab. The contact surface of the slab and the floor is not smooth, and it is additionally filled with a bonding layer. During the drying out of the floor and its contraction, this kind of connection causes an additional system of internal forces close to the surface of the slab and the floor, namely squeezing the slab and stretching the floor (Fig. 4). The resulting contraction stresses are to be transferred through the co-polymer fibres added to the concrete.

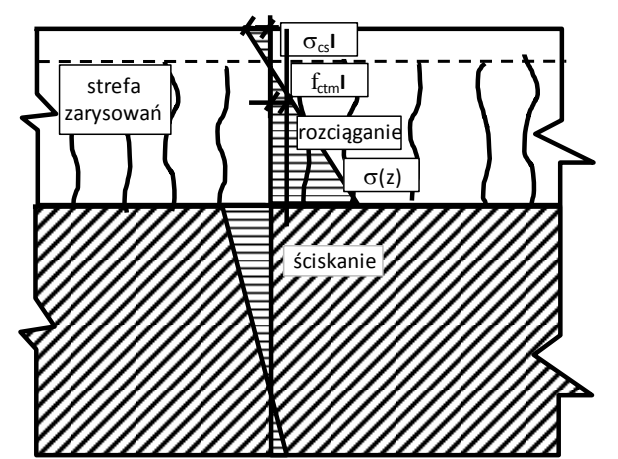

Fig. 4. Distribution of stresses in two slabs; the lower slab is older and the upper slab is younger and still maturing
Theoretically required minimum reinforcement made of steel rods, due to the limitation of cracks' width to the value of $0.3 \mathrm{~mm}$, varies depending on the use of the stretched zone of the floor from $20 \mathrm{~cm}^{2} / 1 \mathrm{~m}$ length to $50 \mathrm{~cm}^{2} / 1 \mathrm{~m}$ length. The minimum reinforcement due to contraction caused by the location of the new concrete floor layer upon the one-year-old concrete of the foundation slab is rounded to $8.5 \mathrm{~cm}^{2} / 1 \mathrm{~m}$ length $10.1 \mathrm{~cm}^{2} / 1 \mathrm{~m}$ length. Requirements for transferring the anticipated shrinkage in the floor have been transferred to reinforcement with co-polymer fibres

The course of the shrinkage in the slab and the floor could have occurred as follows:

- Construction of the concrete slab in December 2013.

- Maintenance of the slab until it achieved minimal strength, self-balanced contraction appeared during the maintenance.

- After the maintenance phase had been completed, the drying process occurred. Selfbalanced shrinkage stresses increased to a level when moisture flow from the slab to the surroundings stabilized. Tensile stresses in the concrete could have exceed the tensile strength of the concrete and cracking of the upper surface of the slab could have occurred up to about $20 \%$ of its height.

- Deformation (and the accompanying tensile stresses in the concrete of the slab) systematically increased from autogenous shrinkage and drying. After one year, they reached a value of up to $20 \%$ of total shrinkage stresses. $80 \%$ of the shrinkage deformations will take place after more than 20 years. After the intensity of diffusion of 
moisture from the slab decreases, the deformations and shrinkage stress decrease. This may occur after a few years from the completion of the slab.

- Anti-shrink surface reinforcement to be used in the foundation slab should have the surface area of approximately As $=14.1 \mathrm{~cm}^{2}$.

- One year after the slab is made, initial contraction stresses $\sigma_{\mathrm{cs}}$ in the floor can reach the value in the range from $\sigma_{\mathrm{cs}}=\sigma_{\mathrm{cs}}{ }^{\mathrm{II}}+\sigma_{\mathrm{cs}}{ }_{\mathrm{III}}=0.98 \mathrm{MPa}$, and taking into account the stress from the partial fixing of the slab in the diaphragm wall and in the ground $\sigma_{\mathrm{cs}}=\sigma_{\mathrm{cs}}{ }^{\mathrm{I}}+\sigma_{\mathrm{cs}}{ }^{\mathrm{II}}+\sigma_{\mathrm{cs}}{ }^{\mathrm{III}}$ $=6.4 \mathrm{MPa}$ with the assumed tensile strength of concrete equal to $\mathrm{f}_{\mathrm{ctk}}=2.0 \mathrm{MPa}$;

- After a year, the concrete floor was made with co-polymer fibre reinforcement.

- The floor was subjected to maintenance treatment. During this time, moisture from the bottom of the floor penetrated deep into the concrete slab and a contraction was initiated at the point of contact between the slab and the floor. In the places with the existing cracks in the slab, cracks may have been initiated in the floor at the point of contact with the floor as well. Shrinkage stresses that occur in this case may exceed the concrete tensile strength level in the concrete maturing phase. Water supplied during the maintenance onto the upper surface of the floor cannot penetrate the layer of contact between the slab and the floor and prevent rapid loss of water to the drier upper part of the foundation slab.

- Free deformation caused by shrinkage of the floor is blocked by the slab, which does not deform to the same extent as the floor, as there have already been significant deformations in the slab. The floor and the slab are connected by a bonding layer and by uneven contact surface.

- After completion of maintenance, autogenous shrinkage $\left(\left.\right|_{c s} ^{\text {IIa }}\right)$ and drying out $\left(\left.\right|_{c s} ^{\text {IIb }}\right)$ occurred in the upper part of the floor due to the water drainage through the bottom and upper surface of the floor.

- Stresses in the floor subjected to shrinkage deformations should have been transferred by the anti-shrink fibres.

- The slab and floor together undergo a shrinkage process but in a non-homogeneous way due to the large difference in the massiveness of the elements. The floor has a thickness of $\mathrm{m}=130 \mathrm{~mm}$, the slab $-\mathrm{m}=445 \mathrm{~mm}$. Thus, additional stresses arise due to differences in the stiffness of the slab and the floor.

- Shrinkage deformations in the foundation slab increase over time and cause tensile stresses in the floor due to the bonding of to the floor and the slab.

- Contraction stress in the floor $\sigma_{\mathrm{cs}}=\sigma_{\mathrm{cs}}{ }^{\text {II }}+\sigma_{\mathrm{cs}}$ III can reach a value in the range from $\sigma_{\mathrm{cs}}=2.9 \div 5.8 \mathrm{MPa}$ with the assumed average tensile strength of fibre-reinforced concrete equal to $\mathrm{f}_{\mathrm{ctm}}=4.2 \mathrm{MPa}$. The cracks initiated in the foundation slab move to the floor and thus new cracks can form in the floor.

- The minimum structural reinforcement that could transfer tensile stresses from shrinkage without influences coming from shrinkage in the slab should have a value of $\mathrm{A}_{\mathrm{s}}$ from $5.9 \mathrm{~cm}^{2}$ to $10.5 \mathrm{~cm}^{2}$.

- In one of the samples, separation of the foundation slab from the floor was observed, which may indicate that the bonding layer had been cut.

\subsection{Total stress in the foundation slab undergoing stretching}

Stresses due to shrinkage add up to stresses from constant and variables loads affecting the slab and the floor. Shrinkage stress due to creep and relaxation of concrete may decrease. The appropriate relaxation and creeping coefficient $\mathrm{k}_{3}$ for the slab, indicating a smaller share of shrink stresses, is between 0.5 and 0.7 .

Numerous cracks significantly reduce shrinkage stress; on the other hand, they cause an increase in the total deformation and deflection of both the slab and the floor.Estimated 
calculations indicate exceeding the strength of the reinforced concrete of the foundation slab on the stretched side, but also in places near reinforced concrete pillars, where loads cause compressive stresses. It seems that the stresses of the third type of $\sigma_{c s}{ }^{\mathrm{III}}$ (from selfstress) have a large share in the initial cracking. At the same time due to the limitation of horizontal displacement of the slab forced by contraction: $\sigma_{c s}{ }^{\mathrm{I}}$, horizontal tensile forces arise and increase the value of tensile stresses.

The so-called massiveness of the foundation slab is of great importance, it is $m=2 \mathrm{Ac}_{c} / \mathrm{U}$, and for slabs with one-sided drying, $\mathrm{m}=1 \mathrm{~h}$ (h-slab thickness) $\mathrm{m}=1.25 \mathrm{~m}^{-1}$. The slab belongs to the massive type, which means that the drying process is spread over many years, and the effects of shrinkage from drying are observed over the long use of the facility.

It should be noted that there is also additional pressure from groundwater, from the bottom, which also shits the stress configuration under the foundation slab. Negative deflections of the foundation slab affect the deflection of the floor, which is reinforced only with dispersed fibres. Also, the floor is subjected to significant stretching from shrinkage, as due to the connection with the foundation slab, there is no possibility of free deformation.

\section{Analysis of laboratory test results}

Two samples from core wells (Fig. 5 and 6) were taken from the floor and the foundation slab, and six samples were taken from the floor using the 'pull-off' method (Fig. 7 and 8). Control tests were carried out on the concrete floor using the sclerometric method.

The strength tests determined:

- floor class C20/25 (higher than the planned one),

- class of concrete slab C30/37 (also higher than designed).

The obtained results indicate some discrepancies in the strength of the concrete. Nondestructive measurements may give slightly different results, especially in the case of deeper carbonatation of the cover, as well as in the case of inaccurate concrete thickening over the entire thickness of the cover. In the examined facility, these factors may influence the observed differences in destructive and non-destructive measurements, depending on the place of measurements. Strength values obtained by the sclerometric method were verified on samples taken at the facility at the measurement sites. For further calculations, the results obtained from the correlation of the methods used to determine the strength of concrete were adopted.

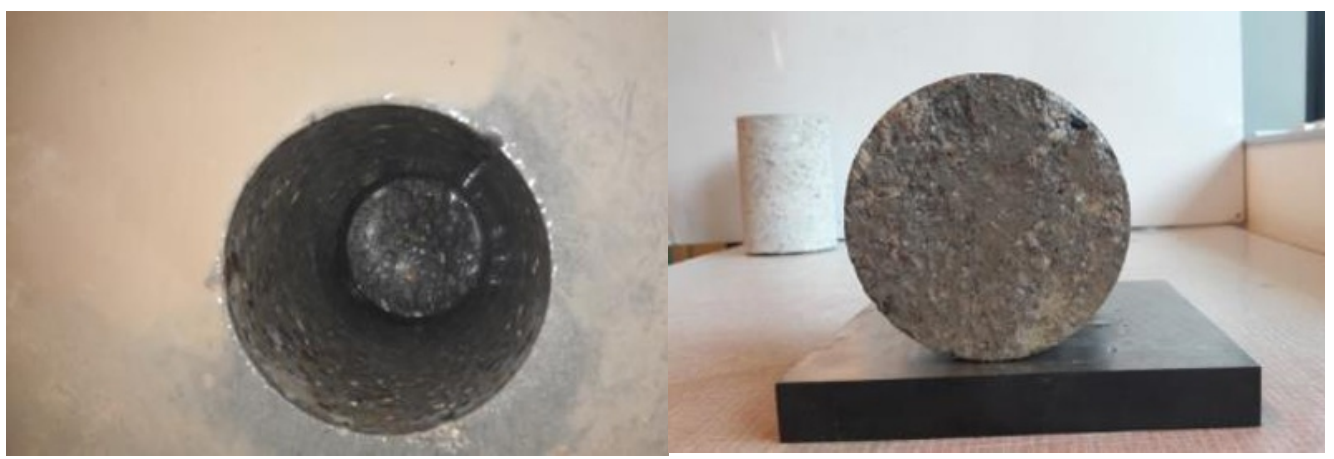

Fig. 5. Place of borehole

Fig. 6. Sample cut from the concrete slab, bonding layer 


\section{Comments on water seepage through reinforced concrete slab and floor}

Problems with foundation slabs exposed to active impact of groundwater are quite common. It was the designers' intention that the technology applied should isolate the foundation slab from the effects of percolating groundwater. Actions involving the location of the diaphragm wall at the level of non-permeable, cohesive soils and thus preventing the inflow of water to the area under the slab proved difficult and partly ineffective. This is related to the presence of stratified soils and aquifers, which are in practice difficult to completely separate from the slab. Therefore, after many years of operation of the facility, groundwater seepage to the foundation slab is observed.

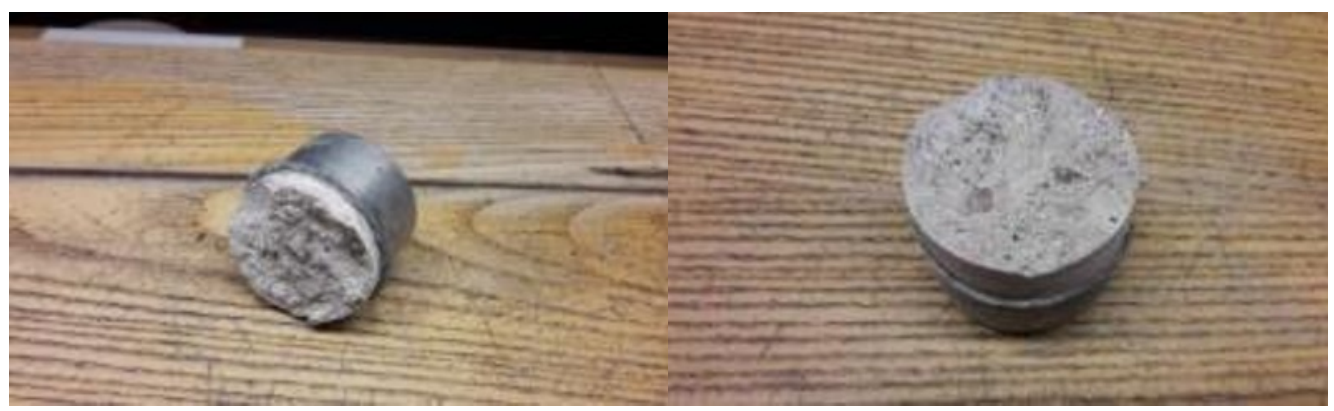

Fig. 7, 8. 'Pull off' samples for strength tests

Increasing value of the water pressure under the foundation slab and water filtration through cracks is a constant process, depending on the amount of water reaching the slab. The appearance of filtration in diaphragm walls after each heavy precipitation proves the existence of this process. Changes in the groundwater level in the area around the building after the construction of the facility have not been measured. Vertical diaphragm walls are a constant obstacle in the flow of groundwater, but at the same time they can dam groundwater up. Awareness of the level of groundwater around the building and under the slab itself (water pressure) would allow it to be periodically pumped out. However, current knowledge allows only to respond to failures that occur by making local injections.

Drilling through the plate and installing a pump would also have some significance for the quality of the injection work carried out with the existing cracks. They would be more effective for 'wet' cracks if they could be carried out under conditions of lowering the water pressure under the slab.

The current construction solution was based on geological research, which showed that there are continuous impermeable layers in which diaphragm walls were anchored. The geological structure of the city, supported by research directly preceding the construction, is basically predictable. Because the seepage of water really exists, one of two circumstances can be indicated as its cause (in the construction phase):

- Local discontinuity of the geological structure, whether it is natural or man-made (e.g. historical drilling through the aquifer during earlier research or bomb blast during the war);

- Construction error consisting in insufficient penetration of the diaphragm wall in the impermeable layer.

Both cases must remain virtually unconfirmed because being random special events with a very small area of impact, it would require a complete unveiling of work done in the ground to determine the causes. On the other hand, these types of events are not really invasive and allow for undesirable phenomena to be overcome by low investments. 
Frequently, a sufficient procedure is to seal the cracks. If hydrostatic pressure in the ground is balanced with the stresses resulting from the static operation of the structure, the phenomenon will cease. Sometimes, additional sealing should be done two or three times. If it is not possible to completely seal the space under the slab, there is a possibility to periodically lower the groundwater level.

\section{Final conclusions}

Cracks in the floor indicate that the Border State of Use is exceeded due to the permissible crack width, but it does not disqualify this structural element from use. The appearance of the so-called 'wet cracks,' however, already requires implementation of repair work at the beginning. The basic reason for the initiation of such cracks is often disregard for contraction stresses. The total contraction pressure cannot be ignored in the calculations and should be neutralised by separately designed near-the-surface reinforcement. Additional increase in stress from hydrostatic pressure as well as interactions between the foundation slab and the floor should also be taken into account.

Appearance of cracking reduces tension in the slab. It is therefore justified to carry out repair (sealing) works on an ongoing basis. Because contraction processes and hydrostatic stresses can increase over time, it should be expected that repair of a particular element will not be a once-off process. Analysis of contraction stress indicates, however, that the number of new cracks appearing will eventually go down.

Developed as part of the research project -" Industrialized construction process (Construction 4.0). Technological and methodological conditions of application of selected composite elements in civil engineering". This project is carried out by the Wroclaw University of Technology together with the Peoples' Friendship University of Russia in Moscow, Research Project PWr-RUDN 2017 no. 45WB/0001/17 Industrialized Construction Process.

\section{References}

1. J. Rybak, A. Ivannikov, E. Kulikova, T. Żyrek, Deep excavation in urban areas-defects of surrounding buildings at various stages of construction, MATEC Web of Conf., 146, 02012, (2018)

2. M. Wyjadlowski, W. Puła, J. Bauer, Reliability of diaphragm wall in serviceability limit states, Archives of Civil and Mechanical Engineering, 15 (4), 1129-1137, (2015)

3. Existing technical documentation

4. K. Kubečka, D. Kubečková, T. Peňáz, M. Marschalko, I. Yilmaz, T. Bouchal, M. Drusa, M. Bendová, M. Duraj, The role of engineering-geological zones in foundation engineering, $12^{\text {th }}$ Int. Multidisciplinary Scientific GeoConf. and EXPO, SGEM 2012, 2 , 339-346, (2012)

5. Z. Muszyński, J. Rybak, A. Szot, Monitoring of structures adjacent to deep excavations. Underground infrastructure of urban areas 2. 177-183, (2012)

6. E. Sawicki, M. Wyjadlowski, Influence of Surrounding Soil Conditions and Joint Sealing on Seepage Resistance of a Sheet Pile Wall, Three Dimensional Numerical Analyses, IOP Conf. Series: Earth and Environmental Science, 95 (2), 022011, (2017)

7. M. Mitew-Czajewska, A study of displacements of structures in the vicinity of deep excavation, Archives of Civil and Mechanical Engineering, 19 (2), 547-556, (2019)

8. W. Starosolski, Reinforced concrete constructions t. I-V. Wydawnictwo Naukowe PWN. Warszawa. 2011-2016

9. K. Flaga, Shrink stresses and near surface reinforcement in concrete constructions PK Kraków 2011 